\title{
Cellular Immunity in COVID-19 Convalescents with PCR-Confirmed Infection but with Undetectable SARS-CoV-2-Specific IgG
}

Sina Schwarzkopf, Adalbert Krawczyk, Dietmar Knop, Hannes Klump, Andreas Heinold, Falko M. Heinemann, Laura Thümmler, Christian Temme, Marianne Breyer, Oliver Witzke, Ulf Dittmer, Veronika Lenz, Peter A. Horn, Monika Lindemann

We investigated immune responses against severe acute respiratory syndrome coronavirus 2 (SARS-CoV-2) among a group of convalescent, potential blood donors in Germany who had PCR-confirmed SARS-CoV-2 infection. Sixty days after onset of symptoms, 13/78 (17\%) study participants had borderline or negative results to an ELISA detecting IgG against the S1 protein of SARSCoV-2. We analyzed participants with PCR-confirmed infection who had strong antibody responses (ratio $>3$ ) as positive controls and participants without symptoms of SARS-CoV-2 infection and without household contact with infected patients as negative controls. Using interferon- $\gamma$ ELISpot, we observed that $78 \%$ of PCRpositive volunteers with undetectable antibodies showed T-cell immunity against SARS-CoV-2. We observed a similar frequency $(80 \%)$ of T-cell immunity in convalescent donors with strong antibody responses but did not detect immunity in negative controls. We concluded that, in convalescent patients with undetectable SARS-CoV-2 IgG, immunity may be mediated through $\mathrm{T}$ cells.

$\mathrm{O}$ ne promising therapeutic option to treat severely ill patients with coronavirus disease (COVID-19) is the use of convalescent plasma (CP) of donors who recovered from severe acute respiratory syndrome coronavirus 2 (SARS-CoV-2) infection (1-3). When searching for potential CP donors with

Author affiliations: Institute for Transfusion Medicine, University Hospital Essen, University of Duisburg-Essen, Essen, Germany (S. Schwarzkopf, D. Knop, H. Klump, A. Heinold, F.M. Heinemann, L. Thümmler, C. Temme, M. Breyer, V. Lenz, P.A. Horn, M. Lindemann); Department of Infectious Diseases, West German Centre of Infectious Diseases, Universitätsmedizin Essen, University of Duisburg-Essen, Essen (A. Krawczyk, O. Witzke); Institute for Virology, University Hospital Essen, University of Duisburg-Essen, Essen (U. Dittmer)

DOI: https://doi.org/10.3201/eid2701.203772
PCR-confirmed SARS-CoV-2 infection, we observed that $17 \%$ of those who volunteered had either borderline or negative results (ratio <1.1) to a SARS-CoV-2 IgG ELISA. We decided to follow up with these volunteers by repeating antibody tests and by assessing T-cell immunity by enzyme-linked immunospot (ELISpot) assay for interferon- $\gamma$ (IFN- $\gamma$ ).

Zhao et al. described the importance of $\mathrm{T}$ cells for the recovery from a structurally related coronavirus, the Middle East respiratory syndrome (MERS) virus, in 2017 (4); Braun et al. speculated that T-cell immunity could also be protective against infection with SARS-CoV-2 (5). Recently, SARS-CoV-2-specific T cells were detected in persons with a history of mild COVID-19 infection and in antibody-seronegative family members of COVID-19 patients (6; F. Gallais et al., unpub. data. https://doi.org/10.1101/2020.06 .21.20132449). However, the seronegative persons in these 2 previous studies either tested negative or were not tested by SARS-CoV-2 PCR. It remains unclear if the T-cell responses detected in SARS-CoV-2 IgGnegative persons without PCR-confirmed infection were induced by SARS-CoV-2 or prior infection with a different coronavirus. In our study, we focused on a cohort with mild PCR-confirmed SARS-CoV-2 infection and undetectable SARS-CoV-2 IgG. This group is unique because it is biased toward male volunteers who felt healthy enough to donate blood.

In this study we established a SARS-CoV-2-specific ELISpot assay and analyzed the T-cell responses in distinct groups of potential blood donors; donors with a previously PCR-confirmed SARS-CoV-2 infection and undetectable or strong spike S1 IgG response; and SARS-CoV-2-negative controls without a history of COVID-19-related symptoms or household contact with infected patients. We furthermore conducted follow-up testing for immunity to 
SARS-CoV-2 until a median of 75 days (range 24-154) after the onset of symptoms and correlated results of SARS-CoV-2-specific T- and B-cell immunity.

The study was approved by the local ethics committee (approval no. 20-9225-BO). All volunteers provided informed consent to participate in the study, which has been performed in accordance with the ethics standards noted in the 1964 Declaration of Helsinki and its later amendments or comparable ethics standards.

\section{Materials and Methods}

\section{Study Participants}

We used a questionnaire to look for potential plasma donors who recovered from SARS-CoV-2 infection. The questionnaire addressed characteristics and additional parameters determining suitability as blood donor (Table). We received $>550$ questionnaires; 310 volunteers had had PCR-confirmed SARS-CoV-2 infection. We selected 78 volunteers (54 male, 24 female) who had PCR-confirmed SARS$\mathrm{CoV}-2$ infection as participants. Their median age was 47 years (19-66) years. We preferred donors who tested negative by a second SARS-CoV-2 PCR and had experience donating blood; we especially sought donors with the blood type $A B$ (because they are universal plasma donors) and donors with a body weight $>60 \mathrm{~kg}$ (because they can donate 3 units of convalescent plasma). We preferentially recruited those living in close vicinity to University Hospital Essen. Because we observed antibodies against human leukocyte antigens and human neutrophil antigens, which prohibited blood donation, mainly in female patients $(n=4)$, we preferred male donors, of whom 1 had these leukocyte antibodies. Only 4 of the participants received oxygen supplementation and none ventilator treatment. Of note, 39/78 participants were infected during skiing holidays. Unfortunately, radiograph and computed tomography data were not available; they are usually performed only for critically ill patients in Germany. Thus, our cohort is unique because it is biased toward especially healthy male blood donors with mild courses of COVID-19. We tested donor serum samples for IgG against the S1 protein of SARS-CoV-2 by ELISA. Furthermore, results of a standard neutralization assay were available in donors with negative or borderline antibody ratios. In the negative control group we included 22 healthy participants (6 male, 16 female) who had no symptoms of SARS-CoV-2 infection and no household

\begin{tabular}{|c|c|c|c|}
\hline Parameter & Ratio $<1.1$ & Ratio 1.1-3.0 & Ratio $>3.0$ \\
\hline All donors & $13(16.7)$ & $24(30.8)$ & $41(52.6)$ \\
\hline Age, y & $45(19-55)$ & $51(28-65)$ & $47(20-66)$ \\
\hline Sex, M/F & $6 / 7$ & $19 / 5$ & $29 / 12$ \\
\hline Body mass index & $25.2(22.3-30.1)$ & $24.9(22.8-28.1)$ & $26.7(22.2-36.8)$ \\
\hline Interval to onset of symptoms, $d$ & $52(32-100)$ & $60(24-98)$ & $64(22-112)$ \\
\hline Stay in risk area/risk contact & 6 & 17 & 20 \\
\hline \multicolumn{4}{|l|}{ Symptoms of COVID-19 infection } \\
\hline Cough & 7 & 19 & 30 \\
\hline Fever & 9 & 13 & 24 \\
\hline Shortage of air & 3 & 4 & 15 \\
\hline Rhinitis & 7 & 7 & 16 \\
\hline Sore throat & 6 & 8 & 15 \\
\hline Limb pain & 7 & 15 & 19 \\
\hline Shivering & 6 & 8 & 15 \\
\hline Diarrhea & 5 & 6 & 15 \\
\hline Weight loss & 3 & 2 & 9 \\
\hline Nausea & 0 & 0 & 4 \\
\hline Loss of appetite & 5 & 3 & 12 \\
\hline Headaches & 7 & 16 & 26 \\
\hline Skin rash & 1 & 1 & 1 \\
\hline Swelling of lymph nodes & 3 & 0 & 2 \\
\hline Loss of sense of smell and taste & 8 & 16 & 18 \\
\hline Necessity of oxygen supply & 0 & 1 & 3 \\
\hline Antimicrobial treatment & 1 & 3 & 7 \\
\hline \multicolumn{4}{|l|}{ Blood group } \\
\hline 0 & 5 & 12 & 16 \\
\hline A & 6 & 8 & 16 \\
\hline $\mathrm{B}$ & 0 & 0 & 6 \\
\hline$A B$ & 1 & 3 & 3 \\
\hline ND & 1 & 1 & 0 \\
\hline
\end{tabular}


contact with infected patients since January 2020. Their median age was 48 years (range $28-60$ years).

\section{Antibody ELISA}

We determined IgG antibodies by a CE-marked Anti-SARS-CoV-2 IgG semiquantitative ELISA (Euroimmun, https:/ / www.euroimmun.com), according to the manufacturer's instructions. The ELISA plates were coated with recombinant SARS-CoV-2 spike protein (S1 domain). Serum samples were analyzed automatically at 1:100 dilution, using the Immunomat (Virion \Serion, https://www.virion-serion. de). Results are given as the ratio of patient sample/ control sample). An antibody ratio of $\geq 1.1$ was considered positive, of $\geq 0.8$ to $<1.1$ borderline, and of $<0.8$ negative.

\section{Virus Neutralization Assay}

Vero E6 cells (ATCC CRL-1586, https://www.atcc. org) and SARS-CoV-2 virus were cultured as described by Heilingloh et al. (7). Neutralization capacity of serum samples was determined by endpoint dilution assay, expressed as $50 \%$ tissue culture infective dose $\left(\mathrm{TCID}_{50}\right) / \mathrm{mL}$. Serial dilutions (1:20-1:2560) of serum samples were incubated with $100 \mathrm{TCID}_{50}$ of SARS-CoV-2 for $1 \mathrm{~h}$ at $37^{\circ} \mathrm{C}$ and added afterwards to confluent Vero E6 cells cultured in 96-well microtiter plates. On day 3 after infection, the cells were stained with crystal violet (Roth, https:/ / www.carlroth.com) and dissolved in 20\% methanol (Merck, https:// www.merck.com); we analyzed the appearance of cytopathic effects (CPE) by light microscopy. The neutralizing titer was defined as the reciprocal of the highest serum dilution at which no CPE breakthrough in any of the triplicate cultures was observed.

\section{ELISpot Assay}

ELISpot stripes containing PVDF membranes (MilliporeSigma MultiScreen HTS; Fisher Scientific, https://www.fishersci.com) were activated with 50 $\mu \mathrm{L}$ of $35 \%$ ethanol for $10 \mathrm{~s}$ and washed with distilled water. Plates were then coated for $3 \mathrm{~h}$ with $60 \mu \mathrm{L}$ of monoclonal antibodies against IFN- $\gamma(10 \mu \mathrm{g} / \mathrm{mL}$ of clone 1-D1K; Mabtech, https://www.mabtech.com). Thereafter, ELISpot plates were washed and then blocked with $150 \mu \mathrm{L}$ AIM-V (Thermo Fisher Scientific, https://www.thermofisher.com). After $30 \mathrm{~min}$ at $37^{\circ} \mathrm{C}$, AIM-V was discarded and duplicates of 250,000 peripheral blood mononuclear cells (PBMC) were grown in the presence or absence of either PepTivator SARS-CoV-2 protein S1/S2 or membrane (M) protein $(600 \mathrm{pmol} / \mathrm{mL}$ of each peptide; Miltenyi Biotec, https://www.miltenyibiotec.com) or an S1 protein
(4 $\mu \mathrm{g} / \mathrm{mL}$; Sino Biologic, https://www.sinobiological. com) in $150 \mu \mathrm{L}$ of AIM-V. The peptide mix (PepTivator) of the S1/S2 protein covered the immunodominant domains, the peptide mix of the M protein, and the complete sequence of the glycoprotein. The S1 protein was a recombinant protein expressed in (human) HEK293 cells (Appendix Figure 1, https://wwwnc.cdc.gov/ EID/article/27/1/20-3772- App1.pdf). After $19 \mathrm{~h}$ incubation at $37^{\circ} \mathrm{C}$, the ELISpot plates were washed and captured IFN- $\gamma$ was detected by incubation for $1 \mathrm{~h}$ with $50 \mu \mathrm{L}$ of the alkaline phosphatase-conjugated monoclonal antibody against IFN-ץ (clone 7-B6-1, Mabtech), diluted 1:200 with phosphate-buffered saline plus $0.5 \%$ bovine serum album. After further washing, $50 \mu \mathrm{L}$ of nitro blue tetrazolium/5-bromo-4-chloro-3-indolylphosphate was added; purple spots appeared within 7 min. Spot numbers were analyzed by an ELISpot reader (AID Fluorospot, Autoimmun Diagnostika GmbH, https://www.aid-diagnostika.com). Mean values of duplicate cell cultures were considered. We determined SARS-CoV-2-specific spots by spot increment, defined as stimulated minus nonstimulated values. Stimulated spot numbers $\geq 3$-fold higher than negative (unstimulated) controls combined with an increment value of $\geq 3$ to any of the 3 antigens were considered positive. Of note, the negative controls reached a mean value of 0.27 spots and an SD of 0.48 (Appendix).

\section{Statistical Analysis}

We performed statistical analysis using GraphPad Prism version 8.0.1 (https://www.graphpad.com) and IBM SPSS Statistics 23 (https://www.ibm.com/ spss/statistics) software. We used linear regression analysis for numerical variables. The analysis of categorical variables was performed by Mann-Whitney test or 1-way analysis of variance (Kruskal-Wallis test) with Dunn's correction for multiple comparisons, as appropriate. Two-sided $p$ values $<0.05$ were considered significant.

\section{Results}

In 78 potential convalescent plasma donors with PCR-confirmed SARS-CoV-2 infection, the median interval between onset of symptoms and first blood sampling was 60 days (range 22-112 days) (Figure $1)$. Thirteen out of $78(17 \%)$ donors had either borderline or negative results (ratio <1.1) to the AntiSARS-CoV-2 IgG ELISA (Euroimmun). Altogether, $28 \mathrm{CP}$ donors were tested again at later time points, a median of 75 days (24-154 days) after onset of symptoms. Retesting in 10 participants with a ratio of $<1.1$ showed that most antibody results $(9 / 10)$ remained similar. The median interval between both 


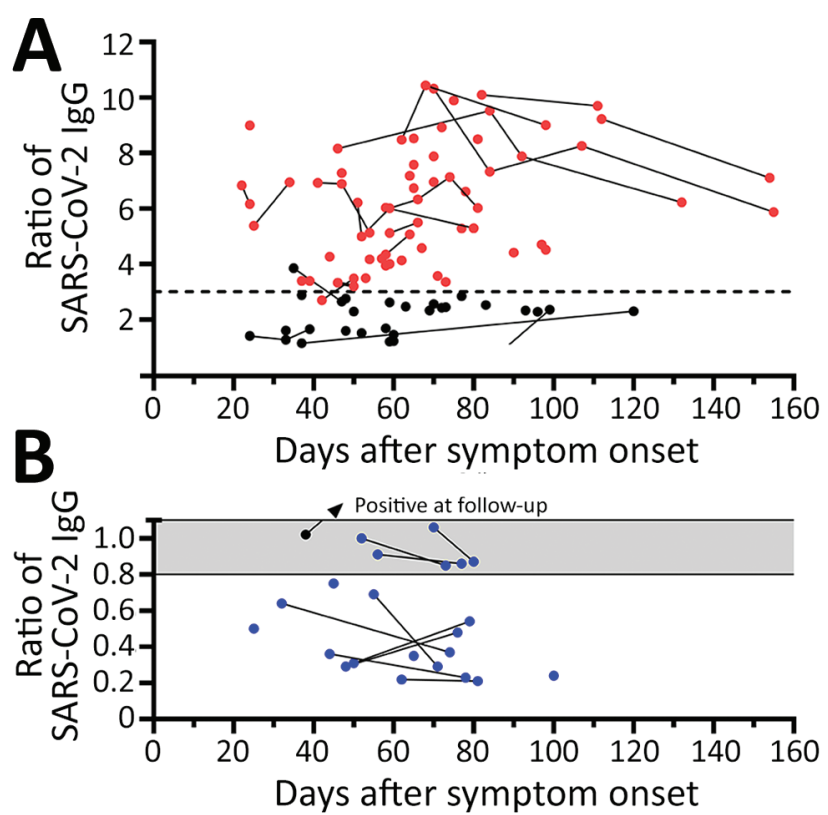

Figure 1. Distribution of SARS-CoV-2 IgG in 78 potential convalescent-plasma donors with PCR-confirmed infection, Germany. Red dots represent study participants with antibody ratio >3; black dots, participants with a ratio of 1.1-3; blue dots, participants with ratio $<1.1$. Sequential data are connected. Horizontal dashed line indicates a ratio of 3 . A) Antibody ratios in the positive or intermediate range. B) Antibody ratios in the borderline or negative range. Gray shading indicates borderline values (ratio of $0.8-1.1$ ); scale is adjusted to enhance data visualization. SARS-CoV-2, severe acute respiratory syndrome coronavirus 2.

blood samplings in this group was 25 days (range 10-61 days). In 1 volunteer with a borderline ratio, the value increased over time and became positive. In donors with higher antibody ratios, the values also remained at a similar level. In all participants with an antibody ratio $<0.8$, no neutralizing antibodies could be found; in those with a ratio of $0.8-1.1$, the titer was 1:20-1:40.

We compared the characteristics of participants with undetectable antibodies to those with intermediate (1.1-3.0) or high antibody ratio (>3) (Table). Of note, in the total cohort of 78 potential blood donors, the median antibody ratio was 3.37; we chose a ratio of 3 as our internal cutoff for convalescent plasma donations. None of the parameters, including age, sex, body mass index, interval to onset of symptoms, risk exposure, symptoms of SARS-CoV-2 infection, need for oxygen or antibiotic treatment, or blood group, differed significantly. However, female participants tended to be overrepresented in the group with undetectable antibodies $(\mathrm{p}=0.1$ by KruskalWallis test). One of the 78 potential $\mathrm{CP}$ donors did not report any symptoms of SARS-CoV-2 infection in the questionnaire. This participant showed an antibody ratio of 3.9.

Cellular immunity was determined from day 24 to day 154 after the onset of COVID-19 symptoms, parallel to antibody testing (Appendix Figure 2). Immunity was followed up as a control in participants with undetectable or low antibodies (irrespective of a triggering event) or when plasma was donated. We established an IFN- $\gamma$ ELISpot assay separately for each of various stimuli, peptide pools of the S1/ S2 and the M protein, and an S1 protein antigen of SARS-CoV-2 (Figures 2, 3). None of the ELISpot responses differed significantly between 9 participants with undetectable antibody responses (ratio <1.1) and 15 with high antibody responses (ratio $>3$ ) (Figure 2). However, ELISpot responses to all stimuli were substantially higher than in the negative controls. Nevertheless, the strength of responses toward the S1 protein tended to be higher in the group with a ratio of $>3$ versus <1.1 (Figure 2, panel A); whereas it was only marginally higher toward the S1/S2 peptides (Figure 2 panel $\mathrm{B}$ ) and similar toward $\mathrm{M}$ peptides (Figure 2, panel C). The strength of responses toward S1/ S2 peptides tended to be higher overall than the S1 protein alone. $\mathrm{CP}$ donors with an antibody ratio $<1.1$ showed a median frequency of 3 spots per 250,000 PBMC for stimulation with S1 protein, 6 with S1/S2 peptides, and 11 with $\mathrm{M}$ peptides. $\mathrm{CP}$ donors with an antibody ratio $>3$ showed a median frequency of 7 spots per 250,000 PBMC with S1 protein, 10 with S1/ S2 peptides, and 13 with $M$ peptides.

To analyze a possible interrelationship between $\mathrm{T}$ cell responses against different SARS-CoV-2 antigens and between T- and B-cell responses, we plotted results of various assays (Figure 3; Appendix Figure 3). We observed that patients whose antibody ratio was $<1.1$ showed robust ELISpot responses mainly directed against the $M$ protein, whereas patients who had a ratio $>3$ had responses similarly directed against S1/S2 or S1 protein and M protein (Figure 3). We furthermore found that cellular responses against S1/ $\mathrm{S} 2$ or $\mathrm{S} 1$ protein were all low (maximum of 13 spots increment against S1/S2 and 5 against S1 protein) in participants with an antibody ratio $<1.1$. In contrast, participants with a ratio $>3$ reached maximum values of 85 (S1/S2 protein) and 32 (S1 protein) spots increment. Maximum responses toward $\mathrm{M}$ peptides were more similar: 39 spots increment in CP donors with a ratio of $<1.1$ or 57 in those with ratio $>3$.

Cellular immunity toward any of the SARSCoV-2 antigens was detectable in 7/9 (78\%) participants who had an antibody ratio $<1.1$. In comparison, $12 / 15(80 \%)$ donors with an antibody ratio of $>3$ had 
detectable cellular immunity. Considering all potential CP donors with PCR-confirmed SARS-CoV-2 infection (also those with a ratio of 1.1-3), 22/28 (79\%) were classified as positive by ELISpot.

In summary, we could detect T-cell immunity against SARS-CoV-2 in most of the SARS-CoV-2 PCRpositive healthy participants with undetectable IgG antibodies against the S1 protein. In this group, T-cell immunity was more strongly directed against the $\mathrm{M}$ than the S1 protein.

\section{Discussion}

We focused on a cohort of volunteer study participants with PCR-confirmed SARS-CoV-2 infection who did not react positive to an S1-specific SARSCoV-2 IgG ELISA. We observed undetectable humoral response in $17 \%$ of our potential blood donors. Similar to our data, other groups reported a lack of antibody response in a subset of patients infected with SARS-CoV-2. For example, a study in China reported absence of antibodies in 10\%-20\% of participants (W. Tan et al., unpub. data, https://doi.org/10.1101/20 20.03.24.20042382). Moreover, Cervia et al. described that, in $15 \%-20 \%$ of S protein-seronegative patients (IgG in the serum), S protein-specific IgA was detectable at several mucosal sites (C. Cervia et al., unpub. data, https://doi.org/10.1101/2020.05.21.108308). Previous publications demonstrated that the magnitude of the humoral response toward SARS-CoV-2 was dependent on the duration and magnitude of viral antigen exposure (8,9; C. Cervia et al.). The absence of durable systemic IgG responses may indicate mild and transient SARS-CoV-2 infection that was cleared effectively (e.g., by the innate immune system) (10). However, whether this transient immune response had led to protective immunity needs to be clarified. The detection of SARS-CoV-2-specific IgG is not considered consistently to be a correlate of virus control (11-13).

Protection of humans against reinfection can be proven definitively only by rechallenge. However, the assessment of cellular immunity can supplement the data on humoral response. The specificity of Tcell assays critically depends on the antigen used for stimulation. In this study, we chose the $S$ protein as stimulus because of its importance as a target for neutralizing antibodies and because it contains major immunodominant epitopes. It mediates the entry of the SARS-CoV-2 virus into the host cell $(14,15)$. The S1 subunit of the $S$ protein acts on the cell binding, and the $S 2$ subunit acts on the fusion of the viral membrane to the cell membrane $(16 ; \mathrm{H}$. Wang et al., unpub. data, https://doi.org/10.1101/2020.03.26.994756). Data by Okba et al. (17) indicate that S1 is the most specific antigen for the diagnosis of COVID-19. The S2 subunit is the more conserved one, and could crossreact with the $S$ protein of severe acute respiratory syndrome coronavirus (SARS-CoV-1) or MERS-CoV $(17,18)$. However, the infection rate with SARS-CoV-1 or MERS-CoV appears low in Caucasian populations. We selected the $\mathrm{M}$ protein, another surface protein of SARS-CoV-2, as a second stimulus because it has been observed to also contain dominant T-cell epitopes (19). It plays a central role in virus assembly (20)
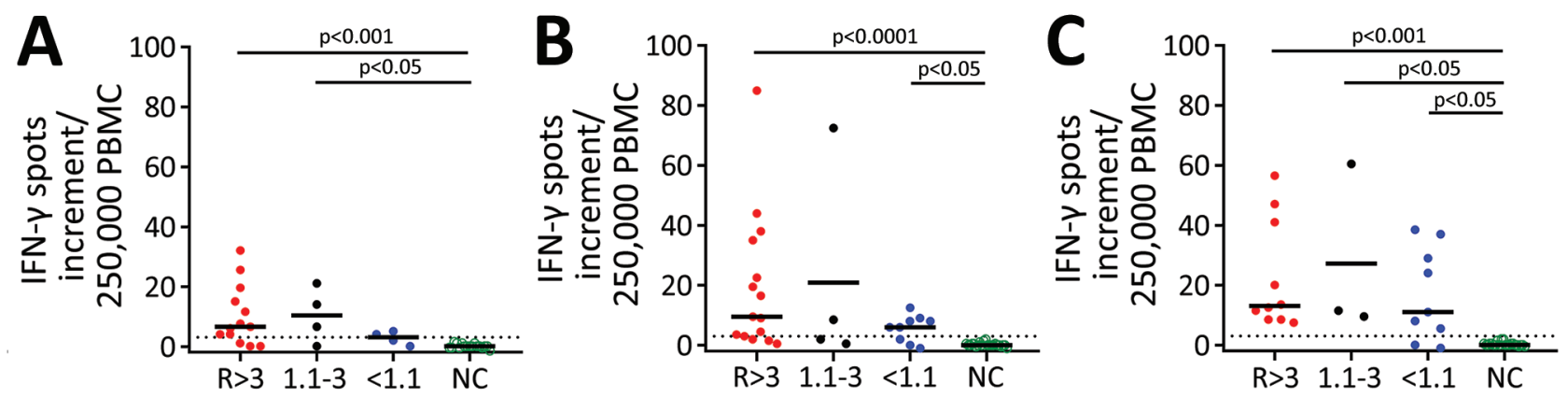

Figure 2. Cellular immunity against severe acute respiratory syndrome coronavirus 2 (SARS-CoV-2) as determined by ELISpot assay in potential convalescent-plasma donors with PCR-confirmed infection, Germany. Peripheral blood mononuclear cells of volunteers were stimulated by an S1 protein antigen of SARS-CoV-2 (A) and by peptide pools of the S1/S2 (B) and the M protein (C). If volunteers were tested sequentially, we only included the first dataset. The 3 left groups represent potential convalescent-plasma donors with PCRconfirmed SARS-CoV-2 infection. They either had a strong positive antibody response to the SARS-CoV-2 IgG ELISA as defined by an antibody ratio $(R)$ of $>3(n=15)$, an intermediate response (ratio of $1.1-3, n=4)$ or borderline or negative results (ratio of $<1.1, n=9$ ). The right group displays data in healthy controls without symptoms of respiratory or gastrointestinal infections and without household contact with SARS-CoV-2 infected patients since January $2020(n=22)$. The group has tested negative or has not been tested by SARS-CoV-2 PCR. Responses in the 4 groups of volunteers were compared by Kruskal-Wallis test with Dunn's correction. Dotted lines represent 3 spots increment. Horizontal lines indicate median values. Stimulation by S1 protein could not be performed in 7 volunteers; stimulation by the $\mathrm{M}$ peptide pool could not be performed in 6 . Red dots represent volunteers with an antibody ratio $>3$; black dots, volunteers with a ratio of $1.1-3$; blue dots, volunteers with ratio $<1.1$; green, NC. IFN- $\gamma$, interferon- $\gamma$; NC, negative controls. 
Figure 3. Interrelationship between results of various severe acute respiratory syndrome coronavirus 2 (SARS-CoV-2)-specific cellular assays in potential convalescent-plasma donors with PCR-confirmed infection, Germany. The plots include the first dataset in potential convalescent plasma donors and in negative controls. Red dots represent volunteers with an antibody ratio $>3$; black dots, volunteers with a ratio of 1.1-3; blue dots, volunteers with ratio $<1.1$; green dots, NC. PBMCs of volunteers were stimulated by peptide pools of the S1/ $\mathrm{S} 2$ and the $\mathrm{M}$ protein and by an S1 protein antigen of SARS-CoV-2. A) Analysis of ELISpot assay with S1/S2 peptides versus M peptides. We performed 2 linear regression analyses separately for potential plasma donors with an $\lg G$ ratio $>3$ and $<1$. 1 . Solid lines show regression lines and dotted lines $95 \% \mathrm{CI}$. B) Analysis of ELISpot assay with S1 protein versus M peptides. ELISpot, enzyme-linked immunospot; IFN- $\gamma$, interferon- $\gamma$; PBMC, peripheral blood mononuclear cells.

and is more likely a target of cross-reactive T cells. Structural comparisons of SARS-CoV-1 and SARSCoV-2 proteins showed $76 \%$ identity for the $S$ protein and more for other structural proteins: $91 \%$ for the envelope protein, 90\% for the M protein, and 95\% for nucleocapsid (19). We observed that potential CP donors with undetectable antibodies against the S1 protein of SARS-CoV-2 had T-cell responses more strongly directed against the $\mathrm{M}$ than the S1 protein. Thus, we speculated that their T cells may preferentially target viral peptides involved in virus assembly rather than cell binding; this hypothesis needs confirmation. Responses toward the S1/S2 peptides were stronger than to the S1 protein, possibly because additional immunodominant T-cell epitopes in the S2 antigen caused the stronger response. The finding that the $\mathrm{T}$-cell responses to the $\mathrm{S} 1$ protein, which is most specific to SARS-CoV-2, were relatively low raises the issue of potential cross-reactivity after stimulation with the S1/S2 or M peptides. Cross-reactivity has been shown for antibodies directed against SARSCoV-1 and SARS-CoV-2 (13).

Similarly, SARS-CoV-2 cross-reactive T cells due to contact to common coronaviruses may occur $(5,21)$ that could interfere with the specificity of our ELISpot assays. Nevertheless, recent PCR-confirmed SARSCoV-2 infection could have caused the frequency of reactive $\mathrm{T}$ cells toward SARS-CoV-2 to be higher in the current cohort of potential $\mathrm{CP}$ donors than those reactive toward other common coronaviruses. Furthermore, cross-reactive $\mathrm{T}$ cells could be protective against SARS-CoV-2 infection, especially in children and young adults with frequent social contacts (5). Using flow cytometry, Braun et al. (5) detected preexisting SARS-CoV-2 S-cross-reactive CD4+ T cells in $34 \%$ of healthy donors, and Grifoni et al. (25) in $\approx 40 \%-60 \%$ of unexposed persons. However, arguing against cross-reactivity interfering with our ELISpot assays, we observed negative $\mathrm{T}$-cell responses in the negative control group.

Of interest, differences between participants with a ratio of $<1.1$ and of $>3$ seem to be more pronounced after stimulation with the S1 protein than the S1/S2 peptides. Thus, apart from the M protein, the S2 protein may be an additional target of T-cell responses, especially in participants with undetectable T- and Bcell responses against the S1 protein.

Chandrashekar et al. observed near-complete protection in 9 rhesus macaques after SARS-CoV-2 infection (22). After initial viral clearance, upon rechallenge, the animals showed a $5 \log _{10}$ reduction in median viral loads compared with primary infection and an anamnestic humoral and cellular immune response. Moreover, Deng et al. reported that viral load remained negative in 4 rhesus macaques upon rechallenge with SARS-CoV-2 but showed a transient increase in body temperature (23). Similarly, Kirkcaldy et al. reported limited evidence of reinfection in humans with previously documented COVID-19 (24). Other studies demonstrated that SARS-CoV-2specific $T$ cells were detectable in the majority of recovered patients (21; N.L. Bert et al., unpub. data, https://doi.org/10.1101/2020.05.26.115832). Data on the earlier coronavirus SARS-CoV-1 indicated 
that cellular immunity was detectable for $>17$ years after infection. Similar to our findings, studies from Sweden and France recently observed $\mathrm{T}$ cell responses against SARS-CoV-2 in seronegative persons (6; Gallais et al.), Sekine et al. reported that 4/31 (13\%) patients who recovered from mild symptoms of COVID-19 were seronegative, which is very similar to $17 \%$ of seronegative results in our cohort. Assessment of $\mathrm{T}$ cell immunity by flow cytometry showed a greater difference of T-cell responses toward S1/ S2 and M peptide pools between seronegative and seropositive patients than our study; this difference may be attributable to several differences between the studies; that is, we here used the ELISpot method instead of flow cytometry to measure specific $\mathrm{T}$ cells and our seronegative CP donors were all PCR positive, whereas none of the $\mathrm{CP}$ donors was tested positive by SARS-CoV-2 PCR (6).

ELISpot data on other coronaviruses have been reported since 2004 . The authors of these early studies used either human leukocyte antigens (HLA)A2 restricted peptides (25) or overlapping peptide pools spanning the whole SARS-CoV-1 proteome (26). ELISpot data in patients in China who recovered from SARS-CoV-1 infection 1 month earlier showed T-cell immunity in $100 \%$ of participants (25), and in $50 \%$ of patients recovered 12 months earlier (26). Our ELISpot data determined at a median of 2 months after the onset of symptoms indicate that $79 \%$ of participants had detectable T-cell immunity, which fits well with the previous data on the structurally related coronavirus SARS-CoV-1. A study on SARS-CoV-1 from 2008 (26) showed that T cell responses were mainly directed against the $S$ protein and that CD8+ T-cell responses were more frequent and of a greater magnitude than CD4+ T-cell responses. Furthermore, a recent study indicated that on day 14 after injection of an adenovirus-vectored COVID-19 vaccine vigorous ELISpot responses against overlapping peptides of the $S$ protein were induced (27). Compared with our data, responses at day 14 were higher. However, compared with a recent study using mosaic surface protein consisting of exposed extracellular domains of the SARSCoV-2 spike, envelope, and membrane proteins (28), we observed slightly stronger T-cell responses in our convalescent patients, although the assays with mosaic surface protein were performed earlier after the onset of symptoms (day 6-32). This difference could be attributable to the use of various stimuli.

As of August 2020, we face the challenge of estimating how many persons are still susceptible to SARS-CoV-2 infection. The ELISpot assay we established may help to identify patients with adaptive immunity against SARS-CoV-2 infection. The assay has the following advantages: it is applicable for routine use, measures cellular immunity within 1 day on a single cell level, determines functional cells, and is independent from HLA restriction. However, it does not allow researchers to determine which T-cell population responds upon restimulation. According to our data in volunteers with confirmed SARS-CoV-2 infection, it could be speculated that the majority of persons with undetectable systemic IgG may presumably be protected by specific T-cell immunity, which would be good news for the control of the pandemic.

\section{Acknowledgments}

We thank Babette Große-Rhode and Martina Filipovic for their excellent technical assistance. We thank all volunteers for their participation and the donation of blood samples.

This study was supported by the Stiftung Universitätsmedizin Essen (A.K.) and the Rudolf Ackermann Foundation (O.W.).

\section{About the Author}

Ms. Schwarzkopf is a bachelor student in medical biology working in the group of M. Lindemann at the Institute for Transfusion Medicine, University Hospital Essen, Germany. The research focus of her group is antimicrobial immune responses in immunocompromised patients.

\section{References}

1. Chen L, Xiong J, Bao L, Shi Y. Convalescent plasma as a potential therapy for COVID-19. Lancet Infect Dis. 2020;20:398-400. https:// doi.org/10.1016/S1473-3099 (20)30141-9

2. Shen C, Wang Z, Zhao F, Yang Y, Li J, Yuan J, et al. Treatment of 5 critically ill patients with COVID-19 with convalescent plasma. JAMA. 2020;323:1582-9. https://doi.org/10.1001/jama.2020.4783

3. Salazar E, Christensen PA, Graviss EA, Nguyen DT, Castillo B, Chen J, et al. Treatment of coronavirus disease 2019 patients with convalescent plasma reveals a signal of significantly decreased mortality. Am J Pathol. 2020 Aug 10 [Epub ahead of print]. https:/ / doi.org/10.1016/ j.ajpath.2020.08.001

4. Zhao J, Alshukairi AN, Baharoon SA, Ahmed WA, Bokhari AA, Nehdi AM, et al. Recovery from the Middle East respiratory syndrome is associated with antibody and T cell responses. Sci Immunol. 2017;2:eaan5393. https://doi.org/10.1126/sciimmunol.aan5393

5. Braun J, Loyal L, Frentsch M, Wendisch D, Georg P, Kurth F, et al. SARS-CoV-2-reactive T cells in healthy donors and patients with COVID-19. Nature. 2020. https:/ / doi.org/ 10.1038/s41586-020-2598-9

6. Sekine T, Perez-Potti A, Rivera-Ballesteros O, Strålin K, Gorin J-B, Olsson A, et al.; Karolinska COVID-19 Study Group. Robust T cell immunity in convalescent individuals with asymptomatic or mild COVID-19. Cell. 2020 
Aug 14 [Epub ahead of print]. https:/ / doi.org/10.1016/ j.cell.2020.08.017

7. Heilingloh CS, Aufderhorst UW, Schipper L, Dittmer U, Witzke O, Yang D, et al. Susceptibility of SARS-CoV-2 to UV irradiation. Am J Infect Control. 2020;S0196-6553(20) 30756-2.

8. Liu Y, Yan LM, Wan L, Xiang TX, Le A, Liu JM, et al. Viral dynamics in mild and severe cases of COVID-19. Lancet Infect Dis. 2020;20:656-7. https:/ / doi.org/10.1016/ S1473-3099(20)30232-2

9. Zhou F, Yu T, Du R, Fan G, Liu Y, Liu Z, et al. Clinical course and risk factors for mortality of adult inpatients with COVID-19 in Wuhan, China: a retrospective cohort study. Lancet. 2020;395:1054-62. https://doi.org/10.1016/ S0140-6736(20)30566-3

10. Tay MZ, Poh CM, Rénia L, MacAry PA, Ng LFP. The trinity of COVID-19: immunity, inflammation, and intervention. Nat Rev Immunol. 2020;20:363-74. https://doi.org/10.1038/ s41577-020-0311-8

11. Ni L, Ye F, Cheng ML, Feng Y, Deng YQ, Zhao H, et al. Detection of SARS-CoV-2-specific humoral and cellular immunity in COVID-19 convalescent individuals. Immunity. 2020;52:971-7 e3.

12. To KK, Tsang OT, Leung WS, Tam AR, Wu TC, Lung DC, et al. Temporal profiles of viral load in posterior oropharyngeal saliva samples and serum antibody responses during infection by SARS-CoV-2: an observational cohort study. Lancet Infect Dis. 2020;20:565-74. https:/ / doi.org/10.1016/S1473-3099(20)30196-1

13. Hoffmann M, Kleine-Weber H, Schroeder S, Kruger N, Herrler T, Erichsen S, et al. SARS-CoV-2 cell entry depends on ACE2 and TMPRSS2 and is blocked by a clinically proven protease inhibitor. Cell. 2020;181:271-80 e8. https:/ / doi.org/ 10.1016/j.cell.2020.02.052

14. Zhou P, Yang XL, Wang XG, Hu B, Zhang L, Zhang W, et al. A pneumonia outbreak associated with a new coronavirus of probable bat origin. Nature. 2020;579:270-3. https:/ / doi.org/ 10.1038/s41586-020-2012-7

15. Wrapp D, Wang N, Corbett KS, Goldsmith JA, Hsieh CL, Abiona O, et al. Cryo-EM structure of the 2019-nCoV spike in the prefusion conformation. Science. 2020;367:1260-3. https:// doi.org/10.1126/science.abb2507

16. Wang C, Li W, Drabek D, Okba NMA, van Haperen R, Osterhaus ADME, et al. A human monoclonal antibody blocking SARS-CoV-2 infection. Nat Commun. 2020;11:2251. https:/ / doi.org/10.1038/s41467-020-16256-y

17. Okba NMA, Müller MA, Li W, Wang C, GeurtsvanKessel CH, Corman VM, et al. Severe acute respiratory syndrome coronavirus 2-specific antibody responses in coronavirus disease patients. Emerg Infect Dis. 2020;26:1478-88. https://doi.org/10.3201/eid2607.200841

18. Jaimes JA, André NM, Chappie JS, Millet JK, Whittaker GR. Phylogenetic analysis and structural modeling of SARS-CoV-2 spike protein reveals an evolutionary distinct and proteolytically sensitive activation loop. J Mol Biol. 2020;432:3309-25. https:/ / doi.org/10.1016/ j.jmb.2020.04.009

19. Ahmed SF, Quadeer AA, McKay MR. Preliminary identification of potential vaccine targets for the COVID-19 coronavirus (SARS-CoV-2) based on SARS-CoV immunological studies. Viruses. 2020;12:254. https:/ / doi.org/10.3390/v12030254

20. Neuman BW, Kiss G, Kunding AH, Bhella D, Baksh MF, Connelly S, et al. A structural analysis of $M$ protein in coronavirus assembly and morphology. J Struct Biol. 2011;174:11-22. https://doi.org/10.1016/j.jsb.2010.11.021

21. Grifoni A, Weiskopf D, Ramirez SI, Mateus J, Dan JM, Moderbacher CR, et al. Targets of $\mathrm{T}$ cell responses to SARS-CoV-2 coronavirus in humans with COVID-19 disease and unexposed individuals. Cell. 2020;181:1489-501. https://doi.org/10.1016/j.cell.2020.05.015

22. Chandrashekar A, Liu J, Martinot AJ, McMahan K, Mercado NB, Peter L, et al. SARS-CoV-2 infection protects against rechallenge in rhesus macaques. Science. 2020;369:812-7. https://doi.org/10.1126/science.abc4776

23. Deng W, Bao L, Liu J, Xiao C, Liu J, Xue J, et al. Primary exposure to SARS-CoV-2 protects against reinfection in rhesus macaques. Science. 2020;369:818-23. https:/ / doi.org/ 10.1126/science.abc5343

24. Kirkcaldy RD, King BA, Brooks JT. COVID-19 and postinfection immunity. JAMA. 2020;323:2245-6. https://doi.org/10.1001/jama.2020.7869

25. Wang YD, Sin WY, Xu GB, Yang HH, Wong TY, Pang XW, et al. T cell epitopes in severe acute respiratory syndrome (SARS) coronavirus spike protein elicit a specific T-cell immune response in patients who recover from SARS. J Virol. 2004;78:5612-8. https:/ / doi.org/10.1128/ JVI.78.11.5612-5618.2004

26. Li CK, Wu H, Yan H, Ma S, Wang L, Zhang M, et al. $\mathrm{T}$ cell responses to whole SARS coronavirus in humans. J Immunol. 2008;181:5490-500. https:/ / doi.org/10.4049/ jimmunol.181.8.5490

27. Zhu FC, Li YH, Guan XH, Hou LH, Wang WJ, Li JX, et al. Safety, tolerability, and immunogenicity of a recombinant adenovirus type-5 vectored COVID-19 vaccine: a doseescalation, open-label, non-randomised, first-in-human trial. Lancet. 2020;395:1845-54. https:// doi.org/10.1016/ S0140-6736(20)31208-3

28. Thijsen S, Heron M, Gremmels H, van der Kieft R, Reusken C, Kremer K, et al. Elevated nucleoprotein-induced interferon- $\gamma$ release in COVID-19 patients detected in a SARS-CoV-2 enzyme-linked immunosorbent spot assay. J Infect. 2020;81:452-82. https:/ / doi.org/10.1016/ j.jinf.2020.06.015

Address for correspondence: Monika Lindemann, Institute for Transfusion Medicine, Robert-Koch-Haus, Virchowstr 179, University Hospital Essen, 45147 Essen, Germany; email: monika. lindemann@uk-essen.de 